Portland State University

PDXScholar

$11-2021$

\title{
An Adjustable Stiffness Torsional Magnetic Spring with a Linear Stroke Length
}

\author{
Dawei Che \\ Portland State University, dawei2@pdx.edu \\ Jonathan Z. Bird \\ Portland State University, bird@pdx.edu \\ Alex Hagmüller \\ Aquaharmonics Inc. \\ Md Emrad Hossain \\ Portland State University
}

Follow this and additional works at: https://pdxscholar.library.pdx.edu/ece_fac

Part of the Electrical and Computer Engineering Commons

Let us know how access to this document benefits you.

\section{Citation Details}

Che, D., Bird, J. Z., Hagmuller, A., \& Hossain, M. E. (2021). An Adjustable Stiffness Torsional Magnetic Spring with a Linear Stroke Length. Institute of Electrical and Electronics Engineers (IEEE). https://doi.org/ 10.1109/ecce47101.2021.9595267

This Post-Print is brought to you for free and open access. It has been accepted for inclusion in Electrical and Computer Engineering Faculty Publications and Presentations by an authorized administrator of PDXScholar. Please contact us if we can make this document more accessible: pdxscholar@pdx.edu. 


\section{An Adjustable Stiffness Torsional Magnetic Spring with a Linear Stroke Length}

\author{
Dawei Che \\ Department of Electrical and \\ Computer Engineering \\ Portland State University \\ Portland, OR, 97201, USA \\ dawei2@pdx.edu
}

\author{
Jonathan Z. Bird \\ Department of Electrical and \\ Computer Engineering \\ Portland State University \\ Portland, OR, 97201, USA \\ jonathan.bird@ieee.org
}

\author{
Alex Hagmüller \\ Aquaharmonics Inc. \\ Portland, OR, 97068, USA \\ aquaharmonics@gmail.com
}

\author{
Md Emrad Hossain \\ Department of Electrical and \\ Computer Engineering \\ Portland State University \\ Portland, OR, 97201, USA \\ mdemrad@pdx.edu
}

\begin{abstract}
This paper presents the analysis, mechanical design, and proof-of-principle experimental testing of a new type of adjustable stiffness torsional magnetic spring for an ocean generator application. Unlike prior published designs the rotary magnetic spring is shown to have a highly linear adjustable stroke length. The presented torsional spring is experimentally shown to be able to create $a \pm 45^{\circ}$ angular stroke range with a peak torque of $\pm 39.1 \mathrm{~N} \cdot \mathrm{m}$. The stiffness is adjusted by using a stepper motor to axially adjust the axial magnet offset. The stepper motor contains a brake so that power is not expended when maintaining a desired spring stiffness. It is shown that by using a series spring arrangement the stroke length can be extended to $\pm 90^{\circ}$.
\end{abstract}

Keywords-Finite element analysis, permanent magnet, springs, variable stiffness

\section{INTRODUCTION}

Variable stiffness magnetic torsional springs have recently been studied for use in soft robotic joint applications [1-3] and servo motor applications [4]. The use of parallel or series variable stiffness springs in oscillatory tasks can reduce the peak power requirements of the drive motor and improve efficiency [5]. Adjustable stiffness magnetic springs also have the potential for increasing the power generating capabilities of ocean generators $[6,7]$. In many of the ocean generator designs the stiffness needs to be negative.

Torsional magnetic springs can adjust their stiffness by axially moving the magnet rotors and locking the axial position in place [1-4]. While the energy density of a magnetic spring is lower than their mechanical counterparts the magnetic springs non-contact operating capability enables it to have higher reliability and a longer service life [4]. In addition, the magnetic operation of the spring enables the stiffness to be adjusted to have both a positive and a negative stiffness more easily than their mechanical spring counterparts [8-11]. A magnetic spring also has low hysteresis loss.

All fixed stiffness and variable stiffness magnetic torsional springs published to-date $[1-4,12]$ have a non-linear stiffness and this limits their stroke length range and prevents the spring

This research in funded in part by the Department of Energy's Office of Energy Efficiency and Renewable Energy (EERE) under the water power Technologies Office, Award number DE-EE0001837. from being used in series. In this paper a new type of adjustable stiffness torsional magnetic spring is presented that exhibits a high degree of linearity. The adjustable stiffness magnetic spring is being developed for use within an ocean generator in which a negative stiffness is needed for resonant mode generation. Along with experimental validation of the new variable stiffness magnetic spring a series topology is presented that shows a method that can be used to further increase the stroke length.

\section{NeW Rotary SpRING TOPOLOGY}

The rotary magnetic spring that has been invented is shown in Fig. 1. The inner rotor is held fixed in place and the outer rotor is allowed to rotate. Fig. 1(a). shows the outer rotor position at the peak torque position. The stiffness value is adjusted by axially translating the outer rotor. Fig. 1(b). shows the axial position at the zero torque, zero stiffness position, (at which the spring acts like a clutch). The outer rotor support is made of ferromagnetic (1018) steel.

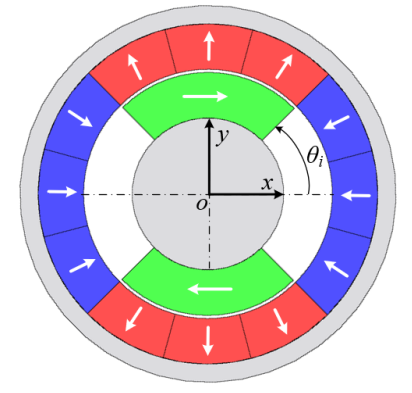

(a)

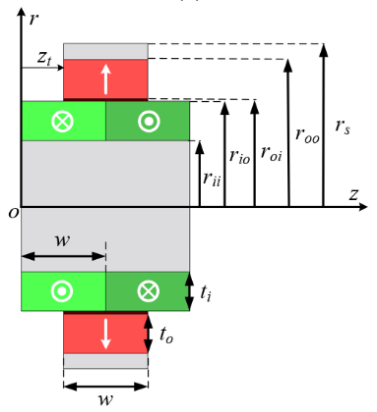

(b)

Fig. 1. (a) Front view of the variable stiffness torsional magnetic spring and (b) cut-through view showing parameter definitions. The inner rotor core is made of 6061 Aluminum, the outer rotor core is made of 1018 steel. 
Using the initial design geometric parameters shown in Table I and $\mathrm{N}-50$ grade magnets the torque vs. stroke length relationship was computed using 3-D finite element analysis (FEA) for different axial offset positions. The proof-of-principle prototype dimensions, shown in Table I, were selected based on the requirement to build a small prototype for demonstration purposes. The torque as a function of stroke length and angular position is shown in Fig. 2 and Fig. 3. By translating the outer rotor it is shown that at a given angle both negative and positive stiffness can be equally obtained. The peak torque value, at $\theta_{i}=$ $45^{\circ}$, was computed to be $T_{m}=39.1 \mathrm{~N} \cdot \mathrm{m}$. At $z=16 \mathrm{~mm}$ the outer rotor is between the two inner rotors, as illustrated in Fig. 1(b). and this results in zero torque. The coefficient of determination [13], denoted as $r^{2}$, can be used to evaluate the level of linearity. When $r^{2}=1$ a line is completely linear, in the design shown in Fig. 2, the linearity was computed to be $r^{2}=0.998$.

TABLe I. GeOMETRIC Parameters

\begin{tabular}{|c|c|c|c|}
\hline \multirow[b]{2}{*}{ Parameter } & \multicolumn{2}{|c|}{ Proof of Principle Design } & \multirow{2}{*}{$\begin{array}{c}\text { Peak Energy } \\
\text { Density Design } \\
{[\mathrm{mm}]}\end{array}$} \\
\hline & $\begin{array}{c}\text { Initial Design } \\
{[\mathrm{mm}]}\end{array}$ & $\begin{array}{c}\text { Improved } \\
\text { Design [mm] }\end{array}$ & \\
\hline Airgap radius, $r_{g}$ & 40.5 & 30.5 & 40.5 \\
\hline Airgap, $g$ & 1 & 1 & 1 \\
\hline Inner magnet thickness, $t_{i}$ & 15 & 11 & 15 \\
\hline Outer magnet thickness, $t_{o}$ & 15 & 10 & 10 \\
\hline Magnet width, $w$ & 32 & 45.75 & 60.75 \\
\hline Outer back steel radius, $r_{s}$ & 62 & 47 & 57 \\
\hline
\end{tabular}

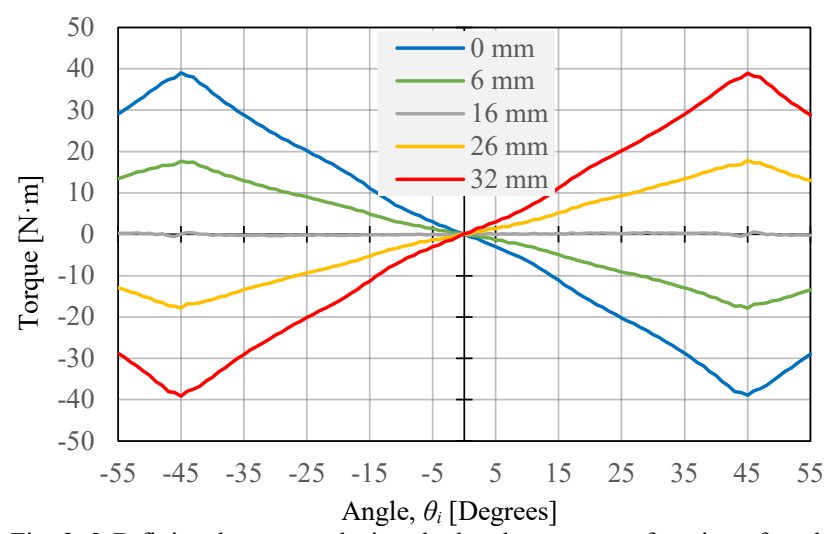

Fig. 2. 3-D finite element analysis calculated torque as a function of angle.

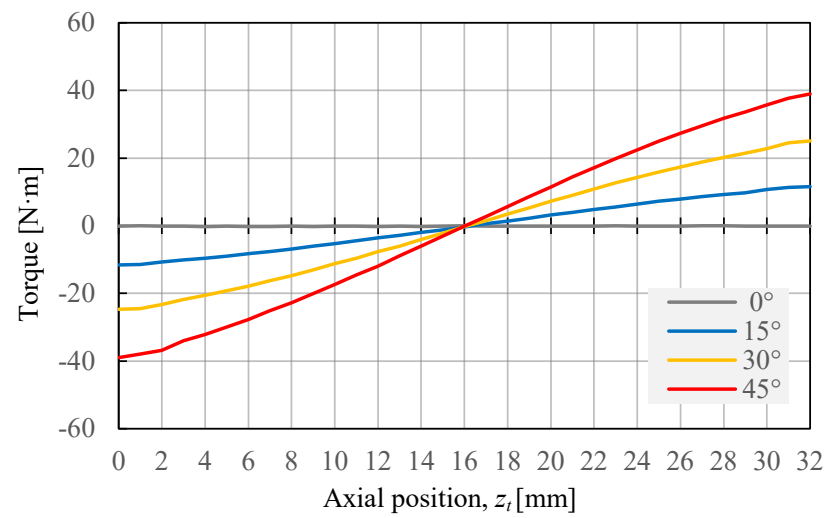

Fig. 3. 3-D finite element analysis calculated torque as a function of axial position.
The torque can be accurately described by

$$
T_{z}\left(\theta_{i}, z_{t}\right)=-\left[k_{\mathrm{m}} \cos \left(\lambda z_{t}\right)\right] \theta_{i}
$$

where

$$
\lambda=\frac{\pi}{z_{m}}
$$

and $k_{m}=49.78 \mathrm{Nm} / \mathrm{rad}$ is the peak stiffness, and $z_{m}=32 \mathrm{~mm}$ is the maximum stroke length.

The required stiffness adjustment force as a function of axial position and angle is shown in Fig. 4 and Fig. 5. Interestingly, the adjustment force is zero at the peak torque angle, $\theta_{i}=45^{\circ}$. This is because the spring must conservative the coupled magnetic energy. The magnetic interaction energy is shifted between the rotary and linear axis during the rotation and translation motion. The force required to adjust the stiffness is high, however the force only needs to be adjusted during stiffness change events and the rotor's axial position is fixed in place using a mechanical brake. As the ocean wave period changes gradually the stiffness adjustment power loss makes up a relatively small percentage of power generation capacity.

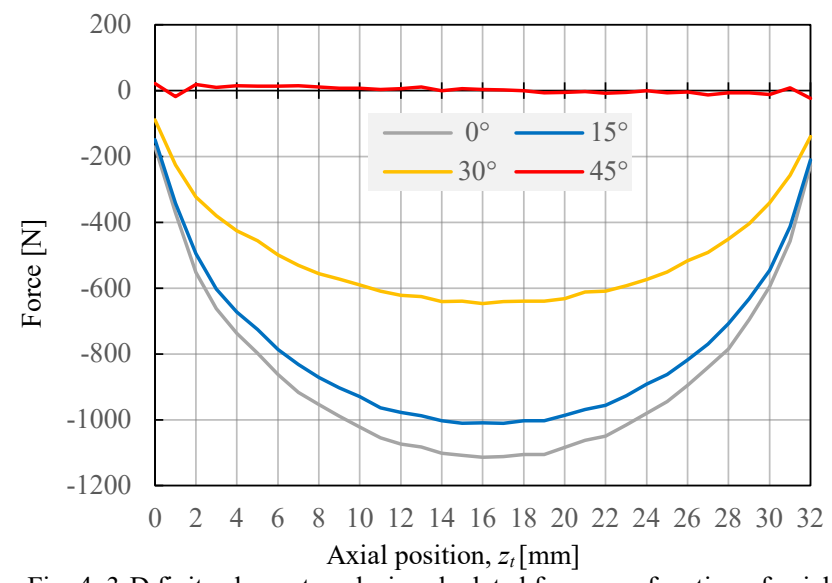

Fig. 4. 3-D finite element analysis calculated force as a function of axial

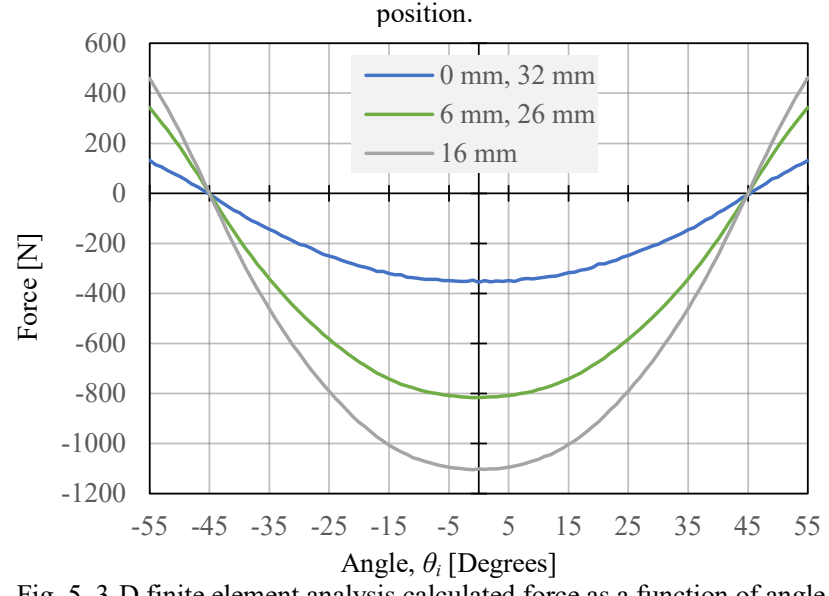

Fig. 5. 3-D finite element analysis calculated force as a function of angle

\section{ENERGY DENSITY SWEEP ANALYSIS}

A sweep parameter analysis was used to improve the energy density of the magnetic spring design. The axial width of the magnetic spring can improve the energy density. Fig. 6 shows 
how the relationship between the mass energy density and width-radius ratio changes. The width-radius ratio is defined as:

$$
\Gamma=\frac{w}{r_{g}}
$$

where, $r_{g}$ is the airgap radius:

$$
r_{g}=\frac{r_{i o}+r_{o i}}{2}
$$

The energy density was computed by using:

$$
E_{d}=\frac{k_{m} \theta_{i}^{2}}{2} \cdot \frac{1}{\rho_{d} \pi w\left[\left(r_{o o}^{2}-r_{o i}^{2}\right)+\left(r_{i o}^{2}-r_{i i}^{2}\right)\right]}
$$

where $\theta_{i}=\pi / 4$ is evaluated at the maximum torque angle. In the initial proof-of-principle design the width-radius ratio $\Gamma=0.79$, was selected however Fig. 7 shows that this results in the mass energy density being $E_{d}=8.39 \mathrm{~J} / \mathrm{kg}$, by selecting a width-radius ratio of $\Gamma=1.5$ the mass energy density increases by $28.9 \%$ to $E_{d}=10.82 \mathrm{~J} / \mathrm{kg}$. This is then $89.67 \%$ of the maximum possible value.

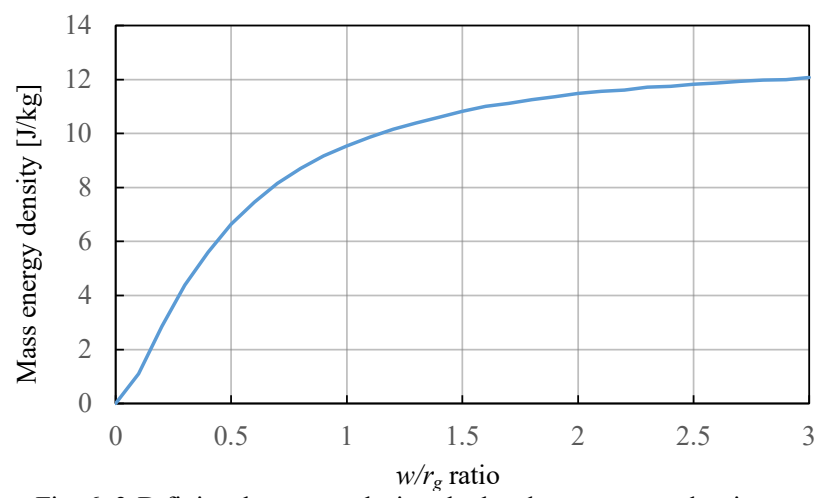

Fig. 6. 3-D finite element analysis calculated mass torque density as a function of width to-radius ratio, $\Gamma$, when $\left(r_{g}, t_{i}, t_{o}\right)=(40.5,15,15)$.

A further improvement in energy density can be obtained by sweeping the magnet thickness and airgap radius. The inner and outer magnet thickness is respectively defined as

$$
\begin{aligned}
& t_{i}=r_{i o}-r_{i i} \\
& t_{o}=r_{o o}-r_{o i}
\end{aligned}
$$

By using the parameters shown in Table II and keeping $\Gamma=1.5$ the sweep analysis results as shown in Fig. 7 were obtained. The design that has the maximum energy density, but higher peak torque, as well as an improved design that achieves the same peak torque as the initial design is shown in Fig. 7. A summary of the geometry parameters and performance metrics for the three designs is shown in Table I and Table III respectively.

TABLE II. SWEEP PARAMETERS

\begin{tabular}{|l|c|}
\hline Airgap radius, $r_{g}$ & {$[30.5,35.5, \ldots 50.5] \mathrm{mm}$} \\
\hline Inner magnet thickness, $t_{i}$ & {$[10,11, \ldots 30] \mathrm{mm}$} \\
\hline Outer magnet thickness, $t_{o}$ & {$[10,11, \ldots 30] \mathrm{mm}$} \\
\hline
\end{tabular}

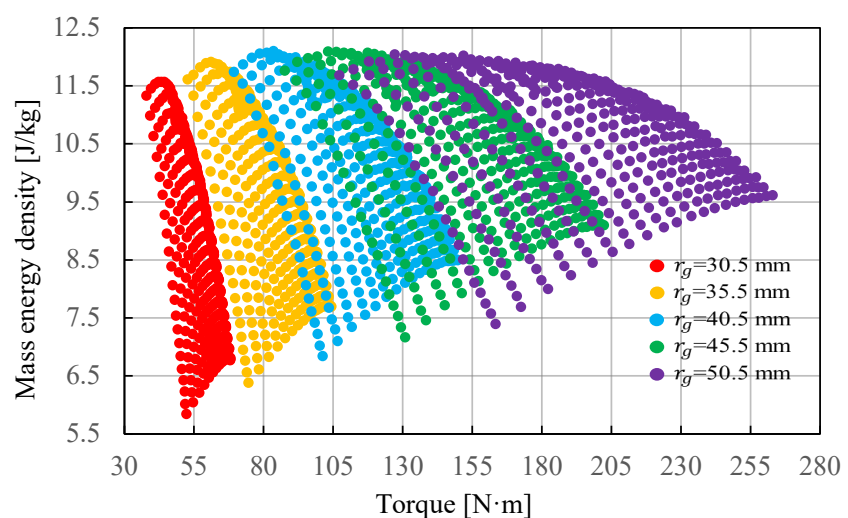

(a)

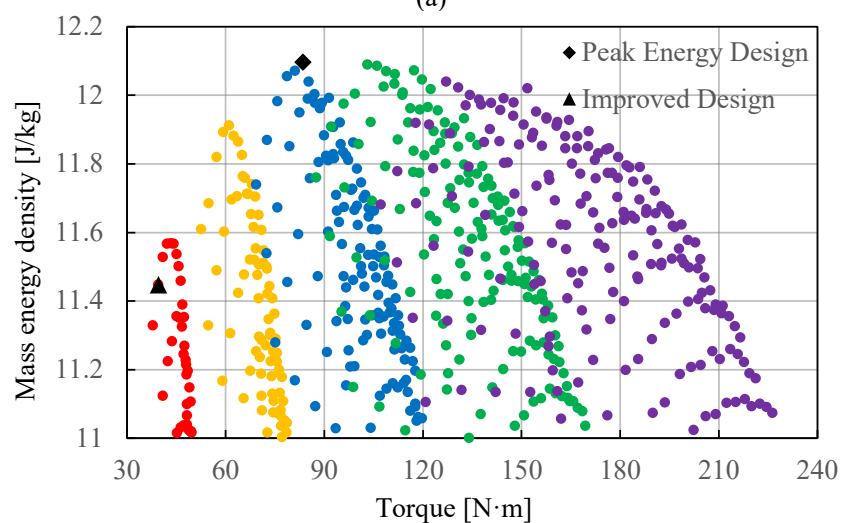

(b)

Fig. 7. (a) 3-D finite element analysis calculated parameter sweep results for the mass torque density as a function of torque and (b) a zoomed in view showing the improved design and peak energy design.

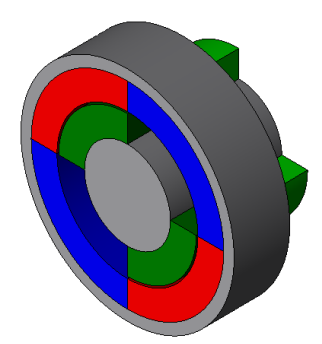

(a)

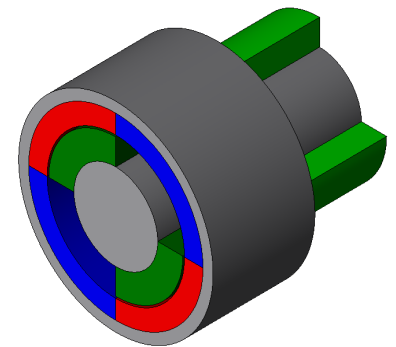

(b)
Fig. 8. (a) Proof-of-principle and (b) peak energy density geometry design

TABLE III. PERFORMANC METRICS

\begin{tabular}{|l|c|c|c|c|}
\hline \multicolumn{1}{|c|}{ Parameter } & $\begin{array}{c}\text { Proof of } \\
\text { Principle } \\
\text { Design }\end{array}$ & $\begin{array}{c}\text { Improved } \\
\text { Design }\end{array}$ & $\begin{array}{c}\text { Peak Energy } \\
\text { Density } \\
\text { Design }\end{array}$ & Units \\
\hline Peak torque & 39.1 & 39.6 & 83.55 & $\mathrm{~N} \cdot \mathrm{m}$ \\
\hline Spring rate & 49.8 & 50.42 & 106.38 & $\mathrm{~N} \cdot \mathrm{m} / \mathrm{rad}$ \\
\hline Peak energy & 15.35 & 15.55 & 32.81 & $\mathrm{~J}$ \\
\hline Active region mass & 1.8 & 1.36 & 2.71 & $\mathrm{~kg}$ \\
\hline \multirow{2}{*}{ Energy density } & 8.39 & 11.45 & 12.10 & $\mathrm{~J} / \mathrm{kg}$ \\
\cline { 2 - 5 } & 62.85 & 85.94 & 90.72 & $\mathrm{~kJ} / \mathrm{m}^{3}$ \\
\hline
\end{tabular}

\section{EXPERIMENTAL VALIDATION}

The torque and force validation was conducted using the initial proof-of-principle experimental setup shown in Fig. 9. The measured torque and force is shown in Fig. 10 and Fig. 11. 
The torque and force were measured by using a Himmelstein (model 48202V) torque transducer and Futek (model LCM300) force transducer. The stiffness was adjusted by using a mechanical turnbuckle and the rotary motion was tested by using an Anaheim Automation stepper motor with a 25:1 gearbox. The measured and computed torque and force were in good agreement. The percentage error in the measurements is shown in Table IV.

TABLE IV. EXPERIMENTAL PROTOTYPE

\begin{tabular}{|l|c|c|c|c|}
\hline Parameter & FEA & Measured & Units & $\begin{array}{c}\text { Difference } \\
{[\%]}\end{array}$ \\
\hline Peak torque & 39.1 & 37.4 & $\mathrm{~N} \cdot \mathrm{m}$ & -4.3 \\
\hline Spring rate & 49.8 & 47.6 & $\mathrm{~N} \cdot \mathrm{m} / \mathrm{rad}$ & -4.4 \\
\hline Peak Energy & 15.35 & 14.69 & $\mathrm{~J}$ & -4.3 \\
\hline Total mass & 1.8 & 1.8 & $\mathrm{~kg}$ & 0 \\
\hline \multirow{2}{*}{ Energy density } & 8.39 & 8.02 & $\mathrm{~J} / \mathrm{kg}$ & -4.4 \\
\cline { 2 - 5 } & 62.85 & 60.12 & $\mathrm{~kJ} / \mathrm{m}^{3}$ & -4.3 \\
\hline Stroke length & $45^{\circ}$ & $45^{\circ}$ & Degrees & 0 \\
\hline Rated angular speed & $\leq 50$ & $\leq 50$ & $\mathrm{r} / \mathrm{min}$ & - \\
\hline
\end{tabular}

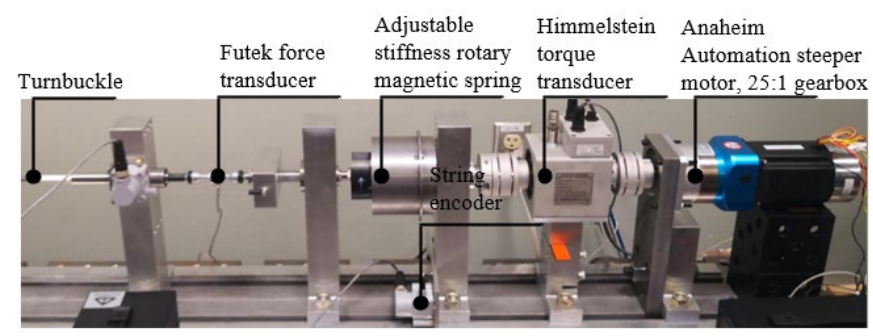

(a)

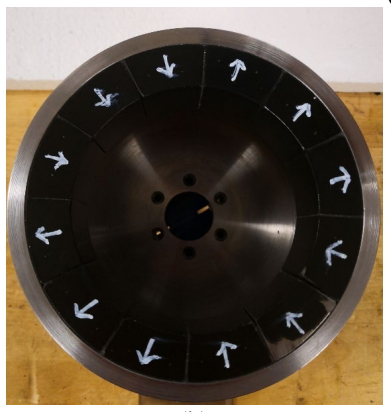

(b)

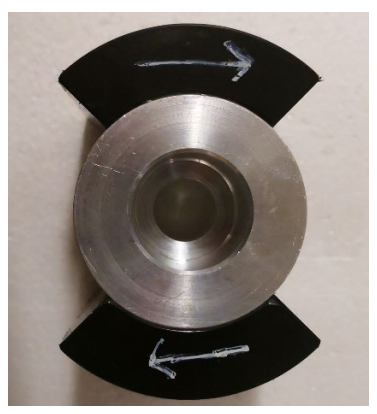

(c)
Fig. 9. (a)Assembled variable stiffness magnetic spring test-stand (b)assembled outer rotor (c)assembled inner rotor.

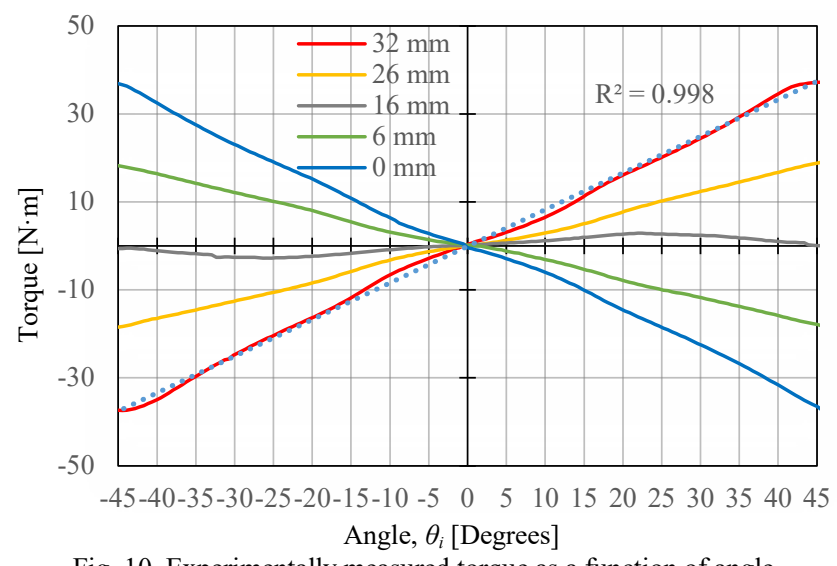

Fig. 10. Experimentally measured torque as a function of angle.

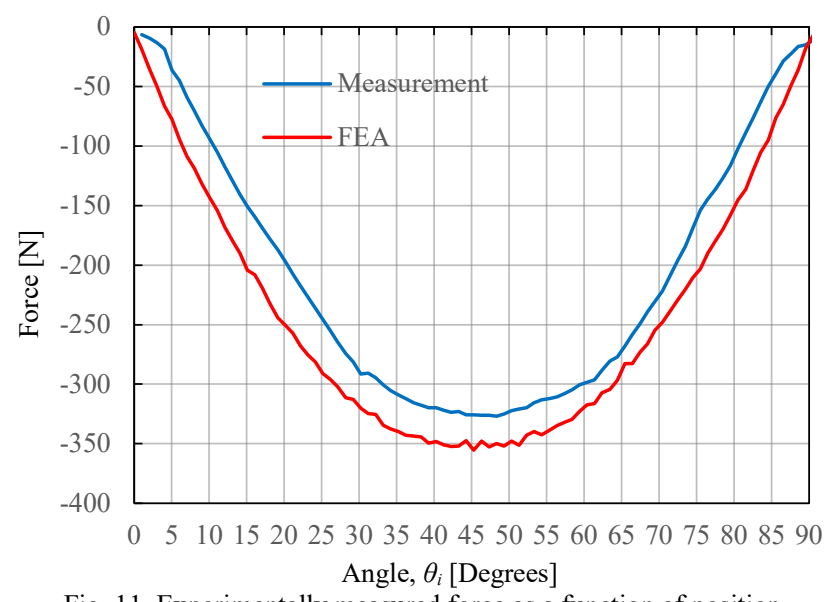

Fig. 11. Experimentally measured force as a function of position.

\section{INCRESED STROKE LENGTH}

Resonant ocean generators that use winch type power takeoffs will require stroke lengths that are much greater than $\pm 45^{\circ}$. As the spring stiffness is constant the springs can be connected in series to increase their stroke length. An example of the $\pm 90^{\circ}$ series torsional spring that is currently being tested is shown in Fig. 12. The assembled inner rotor is shown in Fig. 13. By connecting in series longer stroke lengths can be created. However, the uses of series magnetic springs can only be used with positive stiffness springs unless a mechanism for synchronizing the negative stiffness motion between stages is used.

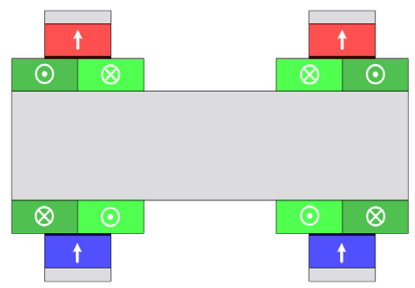

(a)

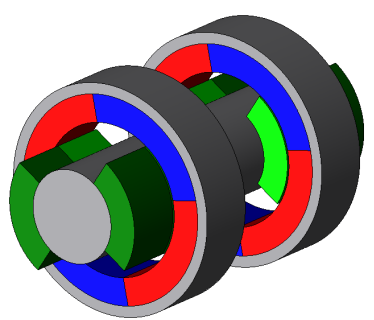

(b)
Fig. 12. (a) Cut through view and (b) perspective view of the $90^{\circ}$ stroke length variable stiffness magnetic spring.

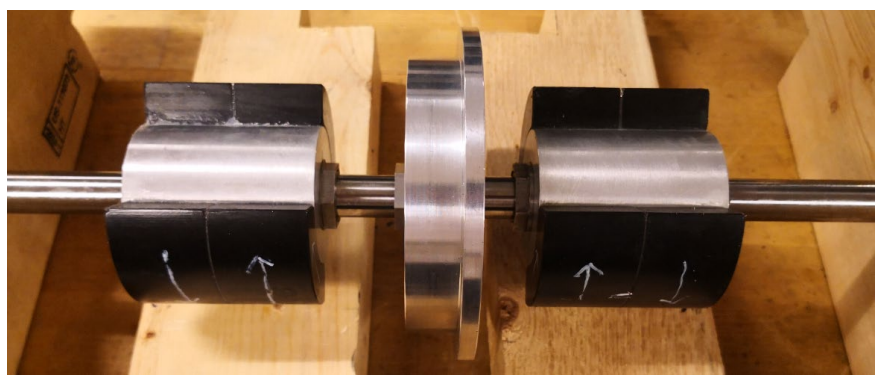

Fig. 13. Assembled $90^{\circ}$ stroke length variable stiffness magnetic spring rotor.

\section{CONCLUSION}

This paper presented the design and experimental testing of a new type of variable stiffness rotary magnetic torsion spring. The magnetic spring is being studied for use in an ocean generation application. The proof-of-principle magnetic spring 
design was shown to provide a peak torque of $39.1 \mathrm{~N} \cdot \mathrm{m}$ with a $\pm 45^{\circ}$ angular stroke range. It was shown that the spring and a high degree of linearity and the stiffness can be adjusted to provide both positive and negative stiffness values. A method of increasing the stroke length further by using a series magnetic spring technique was outlined.

\section{ACKNOWLEDGMENT}

The authors would like to thank the JMAG Corporation for the use of their FEA software.

\section{REFERENCES}

[1] M. W. Hyun, J. Yoo, S. T. Hwang, J. H. Choi, S. Kang, and S. Kim, "Optimal design of a variable stiffness joint using permanent magnets," IEEE Trans. Magn., vol. 43, no. 6, pp. 2710-2712, June 2007.

[2] J. Choi, S. Park, W. Lee, and S.-C. Kang, "Design of a robot joint with variable stiffness," presented at the IEEE International Conference on Robotics and Automation, Pasadena, CA, 2008.

[3] A. Sudano, D. Accoto, L. Zollo, and E. Guglielmelli, "Design, development and scaling analysis of a variable stiffness magnetic torsion spring," Inter. Jouornal of Advanced Robotic Systems, vol. 10, pp. 1-11, 2013.

[4] B. Mrak, B. Lenaerts, W. Driesen, and W. Desmet, "Optimal magnetic spring for compliant actuation - validated torque density benchmark," Actuators, MDPI, vol. 8, Feb. 2019.

[5] T. V. Icon, P. López-García, B. Lenaerts, B. Mrak, D. Lefeber, and B. Vanderborght, "Improving the performance of industrial machines with variable stiffness springs," Mechanics Based Design of Structures and Machines 2020.

[6] P. Moller and J. H. Todalshaug, "Tank testing of high-efficiency phasecontrolled wave energy converter CorPower Ocean, Infrastructure Access Report," 18 Feb. 2015.

[7] M. E. Hossain and J. Z. Bird, "Investigating the Performance of a Variable Stiffness Magnetic Spring for Resonant Ocean Power Generation," in 2019 IEEE Energy Conversion Congress and Exposition (ECCE), 29 Sept.-3 Oct. 2019 2019, pp. 5002-5008, doi: 10.1109/ECCE.2019.8912306

[8] S. Wolf et al., "Variable stiffness actuators: review on design and components," IEEE/ASME Transactions on Mechatronics, vol. 21, no. 5 , pp. 2418-2430, 2016, doi: 10.1109/TMECH.2015.2501019.

[9] C. P. Vo, V. D. Phan, T. H. Nguyen, and K. K. Ahn, "A compact adjustable stiffness rotary actuator based on linear springs: working principle, design, and experimental verification," Actuators, MDPI, vol. 9, no. $141,2020$.

[10] M. Malosio, G. Spagnuolo, A. Prini, L. M. Tosatti, and G. Legnani, "Principle of operation of RotWWC-VSA, a multi-turn rotational variable stiffness actuator," Mechanism and Machine Theory vol. 116 pp. 34-49, 2017.

[11] R. V. Ham, T. G. Sugar, B. Vanderborght, K. W. Hollander, and D. Lefeber, "Compliant actuator designs," IEEE Robotics \& Automation Magazine, vol. 16, no. 3, pp. 81-94, 2009, doi: 10.1109/MRA.2009.933629.

[12] B. E. Paden, C. Chen, and O. J. Fiske, "Magnetic spring and actuators with multiple equilibrium position," Patent 7,265,470 B1, 2009.

[13] J. O. Rawlings, S. G. Pantula, and D. A. Dickey, Applied Regression Analysis: A Research Tool, Second ed. Springer, 1998. 